\title{
The Limiting Current for Reduction of Ferricyanide Ion at Nickel: The Importance of Experimental Conditions
}

\author{
D. A. Szánto \\ National Wind Power, Reading Bridge House, Reading RG1 8LS, U.K.

\section{S. Cleghorn} \\ Applied Electrochemistry Group, University of Portsmouth, Portsmouth PO1 2DT, U.K.
}

\author{
C. Ponce-de-León and F. C. Walsh \\ Electrochemical Engineering Group, School of Engineering Sciences, University of Southampton, \\ Highfield, Southampton SO17 1BJ, U.K.
}

DOI 10.1002/aic.11420

Published online January 29, 2008 in Wiley InterScience (www.interscience.wiley.com).

\begin{abstract}
Steady state, hydrodynamic voltammetry is a well-established technique to measure the rate of mass transport of an electroactive species to, or from, a solid surface electrode in an aqueous electrolyte. Limiting current measurements during the reduction of ferricyanide (hexacyanoferrate ${ }^{I I I}$ ) ion at a nickel rotating disc electrode (RDE) are critically considered, and the accuracy of the technique is quantitatively assessed. The importance of surface pretreatment, type of indifferent electrolyte, and the effect of sunlight are considered. Limiting current values can show large deviations from the values predicted by the Levich equation for laminar flow to a polished RDE when unsuitable conditions are employed, despite the appearance of well-defined limiting current plateaux. Using appropriate pretreatment and experimental procedures, the averaged mass transport coefficients or limiting currents values can be obtained, which are close to the values predicted by the Levich equation for laminar flow to a hydrodynamic smooth RDE. () 2008 American Institute of Chemical Engineers AIChE J, 54: 802-810, 2008

Keywords: activation of electrodes, convective diffusion, electrochemical mass transport, ferricyanide hexacyanoferrate(III) ion, nickel electrode surfaces, limiting current, rotating disc electrode, pretreatment of electrode surfaces, $R D E$, voltammetry
\end{abstract}

\section{Introduction}

The establishment of any electrochemical processes requires feasibility and process design studies. These preliminary works are normally carried out on pilot-scale laboratory

Correspondence concerning this article should be addressed to C. Ponce-de-León at capla@soton.ac.uk.

Current address of S. Cleghorn: Los Alamos National Laboratory, Los Alamos, NM 87545.

(C) 2008 American Institute of Chemical Engineers electrolysers or in small laboratory electrochemical cells, and are essential to design the electrochemical reactor. The successful scale-up from laboratory to industry depends in great measure on the guidance obtained from the results of these investigations and from the continuous evaluation of the process after being implemented.

\section{The limiting current}

The most important figures of merit to be determined during the preliminary studies are often the current efficiency, 


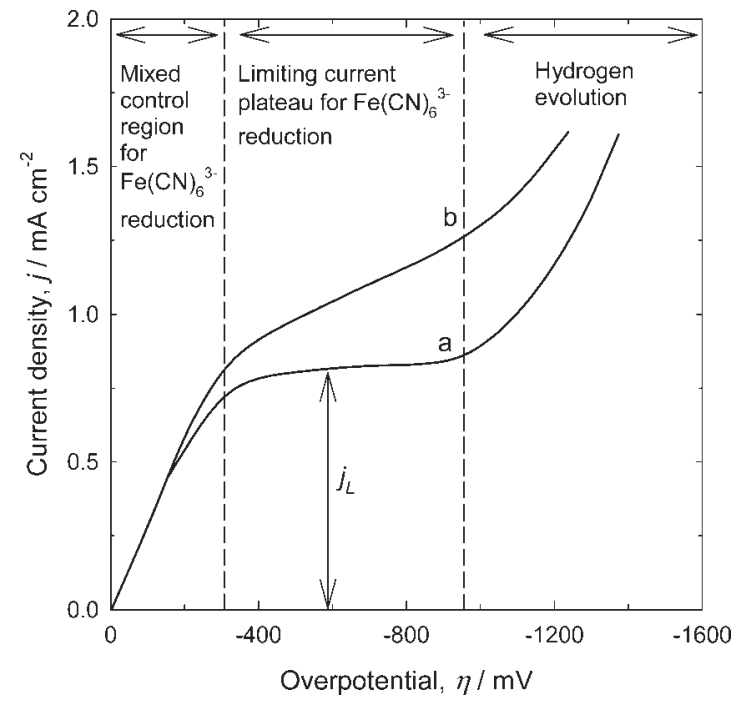

Figure 1. Typical linear sweep voltammograms for the reduction of ferricyanide ion in $1 \times 10^{-3}$ $\mathrm{mol} \mathrm{dm}{ }^{-3} \mathrm{~K}_{3} \mathrm{Fe}(\mathrm{CN})_{6}+10 \times 10^{-3} \mathrm{~mol} \mathrm{dm}^{-3}$ $\mathrm{K}_{4} \mathrm{Fe}(\mathrm{CN})_{6}$ in $0.5 \mathrm{~mol} \mathrm{dm}^{-3} \mathrm{KOH}$ at a RDE $(r=0.25 \mathrm{~cm})$ at $\omega=2000 \mathrm{rpm}$, illustrating the different regions of the curve.

Curve "a" was recorded under for polished and activated electrode conditions, whilst curve " $b$ " was recorded on a roughened surface in sunlight.

the limiting current, and the space time yield. ${ }^{1,2}$ The limiting current is one of the most important figures of merit; its effective determination and maximization is often crucial to the success of an electrochemical process. ${ }^{3}$ Its determination has been a subject of much discussion, and several methods to assure its correct evaluation have been proposed. ${ }^{4-6}$

Typically, mass transport measurements include identification of the limiting current plateau region on a steady state, current vs. potential curve of the type shown in Figure 1, obtained by linear sweep voltammetry. The curve shows three zones: the mixed control region where the primary reaction is controlled by both mass transport and electron transfer; the plateau region where the primary reaction is under complete mass transport control, and the final section where a secondary reaction (typically hydrogen evolution) occurs at the same time as the primary reaction. The limiting current arises due to convective-diffusion of the reactant toward the electrode, and the presence of the plateau indicates that the transport of ions to the working electrode achieved a maximum rate and is the determining step. The measurement of the limiting current is normally carried out on a rotating disc electrode (RDE) and provides one of the simplest methods to measure diffusion coefficients via the Levich equation. ${ }^{7}$ Both curves (a) and (b) in Figure 1 contain the regions described earlier during the reduction of the $\mathrm{Fe}(\mathrm{CN})_{6}^{3-}$ ion on the same electrode and under the same experimental conditions. The difference between the two curves is that a polished and activated electrode was used for curve "a" while a roughened surface electrode under the sunlight was employed in curve " $b$ ". The difference in the two curves reflects the importance of the electrode surface condition on the determination of the limiting current.
In an early contribution, $\mathrm{Wragg}^{8}$ described the advantages of the limiting current diffusion technique for the characterization of chemical reactors, which include (i) accurate, direct, and continuous measurement of mass transport coefficients, allowing time-dependent studies of reactions to perturbations of a system and (ii) precise boundary conditions in comparison to other techniques. The use of the limiting current technique to determine the mass transport characteristics of fixed geometry electrodes was extensively reviewed by Selman and Tobias ${ }^{3}$ in 1978. The importance of limiting current determinations was also considered by Scanell and Walsh. ${ }^{9}$ Important factors that must be taken into account when measuring limiting currents at nickel electrodes include

(i) The state of the nickel surface: the large majority of studies use clean polished nickel, but the pretreatment procedure is rarely seen as critical;

(ii) Cathodic polarization: removal of the oxides formed on the nickel surface electrode before experimental work begins, usually by allowing the evolution of hydrogen and oxide reduction. Many studies either ignore this fact or do not explicitly state the pretreatment conditions used;

(iii) Electrolyte factors: aqueous solutions of potassium ferricyanide degrade in sunlight to produce cyanide ions that can poison the electrode surface. Potassium hydroxide or potassium chloride are among the most common background electrolytes used, but recent studies ${ }^{10,11}$ suggest that the use of potassium carbonate provides more stable limiting current measurement at long times.

(iv) Light conditions: Many studies exclude sunlight from the reactor and from the electrolyte flow system, but this has not been conclusively shown to improve the reliability of data. There is a need to quantitatively assess this effect.

Berger and Ziai ${ }^{12}$ have studied the inconsistencies among various methods used in the literature and have considered that temperature control is crucial to the measurement of a true limiting current. In a later review, Alkire ${ }^{13}$ described mass transport processes, but experimental and preparation conditioning of the electrode surfaces were not considered. Despite the early publication of data describing the necessity of surface pretreatment by Eisenberg et al. ${ }^{14}$ in 1954, many studies have not adhered to suitable surface electrode or process conditions for reliable limiting current data.

\section{The limiting current for the reduction of $\mathrm{Fe}^{I I I} \mathrm{Fe}(\mathrm{CN})_{6}^{3-}$}

The reduction of ferricyanide ion:

$$
\mathrm{Fe}^{\mathrm{III}}(\mathrm{CN})_{6}^{3-}+e^{-} \rightarrow \mathrm{Fe}^{\mathrm{II}}(\mathrm{CN})_{6}^{4-}
$$

under convective-diffusion controlled conditions has become a classical system for mass transport measurements. Platinum or gold electrode surfaces are often preferred, but they are not always feasible in engineering systems because of their cost or availability. ${ }^{1,7}$ Examples of ferricyanide ion reduction include studies reported by Brown et al. ${ }^{15-17}$ Both Marracino et al. ${ }^{18}$ and Montillet et al. ${ }^{19}$ describe studies using nickel foam and nickel felt electrodes, which provide enhanced mass transport and larger surface area. A study by Quickenden and $\mathrm{Xu}^{20}$ stated that inaccuracies in the simplification of the Levich equation exist, and suggested a modified version of an equation proposed by Newman ${ }^{21}$ to compensate for charge-transfer effects during the deposition of copper from 
acid sulphate solutions. When there is no discernible chargetransfer control evident in an electrochemical process, as in the case of $\mathrm{Fe}(\mathrm{CN})_{6}^{3-}$ reduction at a sufficiently negative overpotential, the accuracy of the calculated diffusion coefficient is little improved by the modifications made to the Levich equation by the Quickenden and Xu model. ${ }^{20}$ In the present studies, the use of a conductive background electrolyte ensures that the $\mathrm{Fe}(\mathrm{CN})_{6}^{3-}$ ion migration has a negligible contribution to mass transport.

\section{Comparison of the reduction of ferricyanide ion in different electrochemical systems}

Table 1 shows examples of nickel electrodes used for the electrochemical study of $\mathrm{Fe}(\mathrm{CN})_{6}^{3-} / \mathrm{Fe}(\mathrm{CN})_{6}^{4-}$ redox couple. The diversity of cell geometries and electrode sizes that use this model reaction to characterize the electrochemical system is evident. The most common supporting electrolyte is either potassium hydroxide or sodium hydroxide, and the pretreatment and activation of the electrodes are either not stated or do not follow the recommended procedures reported in the literature such as hydrogen evolution and polarization of the electrode to remove the oxides. The experiments rarely report whether the electrolyte was kept from the sunlight or care was taken during its preparation.

There is a crucial need for quantitative studies of the effect of common experimental factors on the measurement of limiting currents using the ferrocyanide/ferricyanide redox couple at nickel surfaces. This paper demonstrates how the accuracy of limiting currents measured via the reduction of ferricyanide ion is dependent upon factors such as the method and frequency of activation, the state and composition of the substrate, the surface pretreatment, the effect of light on the state and composition of the electrolyte at a constant temperature, and the background electrolyte. RDE studies were used to measure both current vs. potential and current vs. time under well-defined laminar flow conditions. Attention is also drawn to the effect of sunlight on electrolytes containing ferricyanide ion, and quantitative data are provided to show its effect on limiting current measurement.

\section{Theory}

When a potential scan is applied to a working electrode in contact with a particular electroactive species, a polarization curve can be obtained. The current-potential curve contains three main regions: the mixed control, the plateau, and the secondary reaction regions. Considering the data plotted in Figure 1, the plateau region observed between $-400 \mathrm{mV}$ and $-900 \mathrm{mV}$ vs. saturated calomel reference electrode (SCE) occurs due to the restricted transport of ferricyanide ion to the cathode surface. At approximately $-1000 \mathrm{mV}$ vs. SCE, the secondary reaction (evolution of hydrogen gas) occurs and the plateau disappears. The limiting current of the plateau is given by the expression:

$$
I_{\mathrm{L}}=k_{\mathrm{m}} A z F c_{\mathrm{b}}
$$

where $k_{\mathrm{m}}$ is the mass transport coefficient, $A$ is the electroactive area of the electrode, $z$ is the number of electrons involved in the reaction, $F$ is the Faraday constant, and $c_{\mathrm{b}}$ is the bulk concentration of the electroactive species. From this

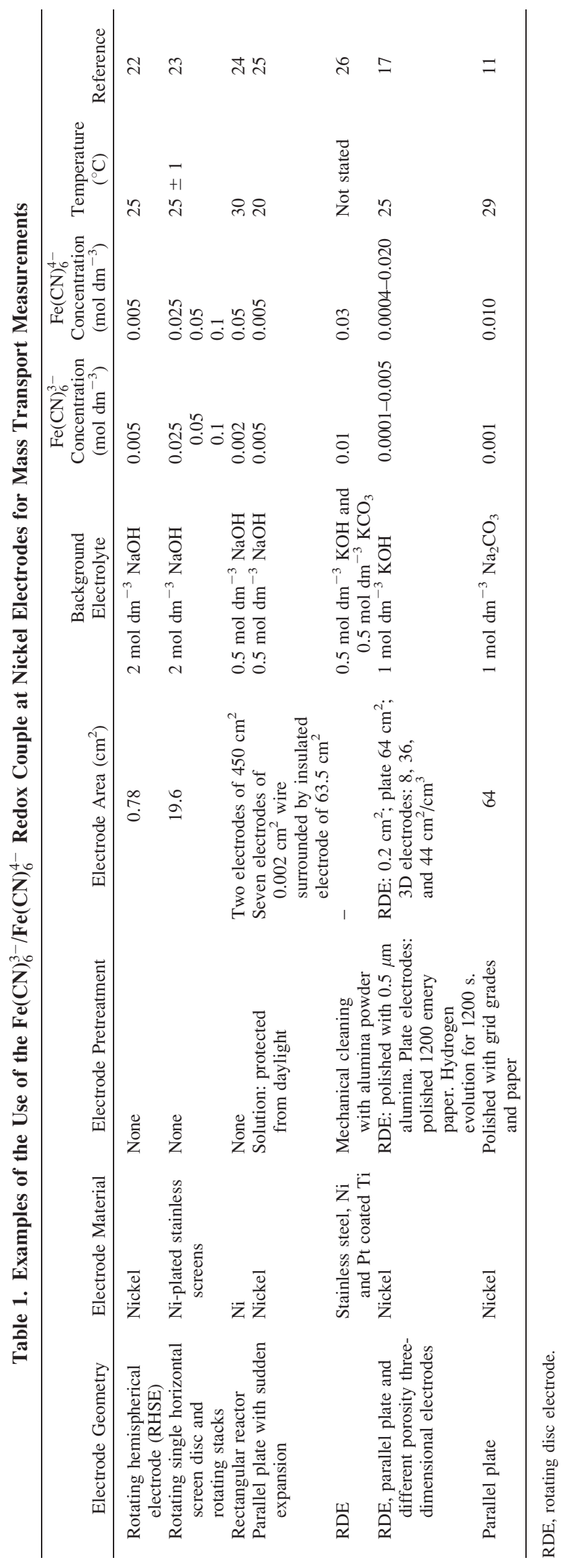

March 2008 Vol. 54, No. 3 AIChE Journal 
equation, values for the mass transport coefficient, which can be used as a figure of merit for a particular chemical reactor, can be established. ${ }^{1}$

Care must be taken in measuring the variable factors in this equation, notably $c_{\mathrm{b}}$ and $A$. Bulk concentration can be easily affected by errors in making up solutions, contamination of solutions, or as in the case of ferricyanide ion, degradation by sunlight over a period of time. The area of the electrode is, of course, highly crucial. Roughness of the electrode surface can increase the active electrode area dramatically, as can factors such as porosity in the case of electrodeposited materials. ${ }^{27}$ In order to compare the results from various electrolyte solutions, it is necessary to calculate the diffusion coefficient obtained from RDE experiments and by the Levich equation ${ }^{7}$ :

$$
I_{\mathrm{L}}=0.62 z F A D^{0.67} v^{-0.167} c_{\mathrm{b}} \omega^{0.5}
$$

where $D$ is the diffusion coefficient, $v$ is the kinematic viscosity, and $\omega$ is the angular velocity. By measuring the limiting current at different rotations speeds, the value of the diffusion coefficient can be calculated from the slope of a plot $I_{\mathrm{L}}$ vs. $\omega^{0.5}$.

\section{Experimental Details}

The RDE consisted of a circular nickel $\operatorname{rod}(r=0.25 \mathrm{~cm})$ sheathed in a PTFE cylinder (outside diameter $=0.70 \mathrm{~cm}$ ), leaving a flat polished circular disc $\left(A=0.196 \mathrm{~cm}^{2}\right)$ exposed to the electrolyte. Three different nickel electrodes were used: (i) plain nickel rod (Johnson Matthey > 99.99 wt \%), (ii) electroplated nickel on carbon steel, and (iii) a nickel coating on carbon steel applied by electroless deposition. For the electroplated nickel, a Watts (sulphate/chloride) nickel bath at a current density of $\approx 10 \mathrm{~mA} \mathrm{~cm}^{-2}$ was used at $60^{\circ} \mathrm{C}$ for $\approx 90 \mathrm{~min}$, to produce a $20-\mu \mathrm{m}$ coating. ${ }^{28}$ Two proprietary electroless nickel baths were employed, namely Nicrolyte 1 and Niklad. Both electroless baths produced a nickel-phosphorus $(9-11 \% \mathrm{P})$ alloy coating of $20-\mu \mathrm{m}$ thick in $1 \mathrm{~h}$. The electrodes were mounted vertically during the deposition of nickel to avoid pitting caused by hydrogen gas sticking to the electrode surface.

The electrolytes used for mass transport measurements were all prepared using analar grade reactant and were freshly prepared for each experiment. The aqueous solution consisted of $1 \times 10^{-3} \mathrm{~mol} \mathrm{dm}{ }^{-3}$ potassium ferricyanide with an excess of $10 \times 10^{-3} \mathrm{~mol} \mathrm{dm}^{-3}$ potassium ferrocyanide, to avoid the oxidation of $\mathrm{Fe}(\mathrm{CN})_{6}^{4-}$ at the counter electrode becoming the rate limiting process. Several background electrolytes were studied, each at a concentration of $0.5 \mathrm{~mol}$ $\mathrm{dm}^{-3}$ : (i) potassium hydroxide, (ii) potassium carbonate, (iii) potassium chloride, or (iv) potassium nitrate. All electrolytes were prepared in doubly distilled water. Prior to use, the solutions were degassed using a fast stream of nitrogen gas for $30 \mathrm{~min}$ to remove dissolved oxygen. Nitrogen was maintained above the electrolyte solution for the duration of the experiment to prevent atmospheric oxygen entering the system. The temperature in all experiments was $298 \pm 1 \mathrm{~K}$.

The polishing procedure for nickel RDE in all the experiments involved: 1200-grade silicon carbide paper moistened with double-distilled water, followed by wet polishing with aqueous slurries containing decreasing sizes of alumina down to particle size of $0.1 \mu \mathrm{m}$. The electrode was degreased with acetone, washed with double-distilled water, and polarized cathodically to evolve hydrogen at $10 \mathrm{~mA} \mathrm{~cm}^{-2}$ in the background electrolyte for $10 \mathrm{~min}$ before each experiment. To minimize the reformation of oxides on the nickel surface, a concentrated solution of $\mathrm{K}_{3} \mathrm{Fe}^{\mathrm{III}}(\mathrm{CN})_{6}$ and $\mathrm{K}_{4} \mathrm{Fe}^{\mathrm{II}}(\mathrm{CN})_{6}$ was injected into the electrolyte, such that the final electrolyte contained the desired concentration of ferricyanide ion. Where required, ferricyanide ion concentration was measured using UV-visible spectroscopy on a diode-array spectrophotometer (Hewlett Packard 8452A) that was calibrated using standardized solutions and a $\lambda_{\max }$ of $302 \mathrm{~nm}$. The extinction coefficient of potassium ferricyanide in aqueous potassium hydroxide $\left(0.5 \mathrm{~mol} \mathrm{dm}^{-3}\right)$ was measured as $1.014 \pm 0.002$ $\mathrm{mol} \mathrm{L} \mathrm{cm}^{-1}$.

The electrochemical apparatus consisted of a $1 \mathrm{~A} / 10 \mathrm{~V}$ potentiostat (Thompson Electrochem Autostat), controllable by a linear potential sweep generator (Pine Instruments). Current-potential curves were recorded on a standard $x-y$ chart recorder Bryans 2000. The RDE drive (Thompson Electrochem) provided electrical connections to the potentiostat and rotation speeds up to $3500 \mathrm{rpm}$. The RDE cell was a conventional three-compartment, glass cell. The working and counter electrode compartments were separated by a Nafion ${ }^{\circledR}$ 324 cation exchange membrane. The SCE was positioned at $\sim 1 \mathrm{~mm}$ from the surface of the working electrode by means of a Luggin capillary containing the same electrolyte as the working electrode compartment. Steady state linear sweep voltammograms were recorded at a linear potential sweep of $1 \mathrm{mV} \mathrm{s}^{-1}$ from the rest potential to a sufficiently negative value for hydrogen evolution at the electrode surface (typically, $1200 \mathrm{mV}$ vs. SCE). The change of limiting current with time was monitored with a computer connected to the potentiostat via the serial port; an inhouse program, AutoForm 1.0, was written to control the potentiostat and to measure and to record current values at 0.1 -s intervals.

\section{Results and Discussion}

\section{Effect of the surface activation: Pretreatment}

Most electrochemical studies using the reduction of ferricyanide ion to measure mass transport characteristics activate the nickel surface electrode before the experiments. However, sometimes the procedure can be easily overlooked, especially in experiments involving flow-through systems. In these cases, the limiting current plateau could look flat and well defined, but often the wrong mass transport data can be obtained. Other times, the pretreatment procedure is not recorded. To illustrate the importance of surface activation, limiting currents were measured for a series of sweep rates on different electrode surfaces and plotted against the square root of the rotation speed. The current values to construct the Levich plots shown in Figure 2 were measured in the middle of the limiting current plateau, and more details of the procedure can be found in Ref. 29. In one series of experiments, the electrode was activated prior to each linear sweep; in the other set, the electrode was activated once, at the start, then all experiments were performed on the same surface with no further activation. These are referred as "multiple" and "single" activation, respectively; Table 2 shows the diffusion 


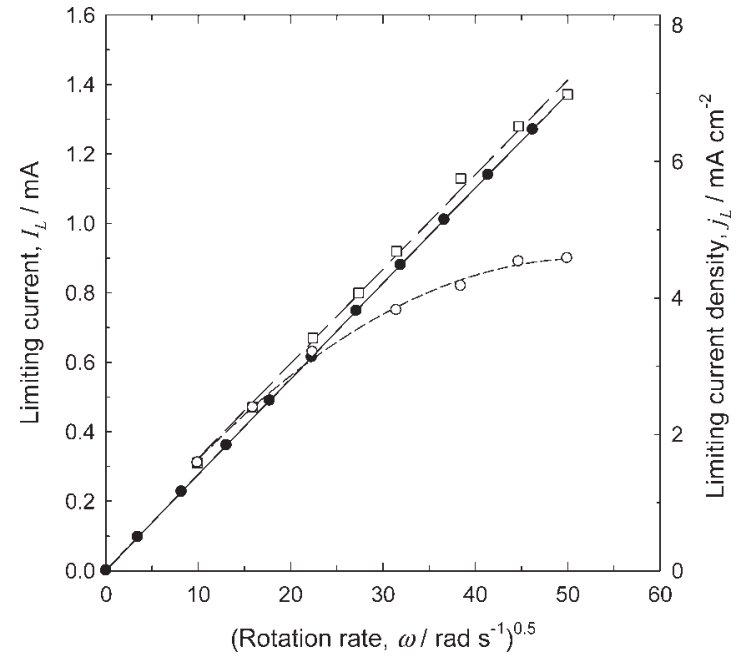

Figure 2. Levich plot of limiting current density $\left(i_{L}\right)$ vs. square root of rotation speed for the reduction of ferricyanide ion in $1 \times 10^{-3} \mathrm{~mol} \mathrm{dm}^{-3}$ $\mathrm{K}_{3} \mathrm{Fe}(\mathrm{CN})_{6}+10 \times 10^{-3} \mathrm{~mol} \mathrm{dm}^{-3} \mathrm{~K}_{4} \mathrm{Fe}(\mathrm{CN})_{6}$ in $0.5 \mathrm{~mol} \mathrm{dm}^{-3} \mathrm{KOH}$ at an activated nickel $\operatorname{RDE}(r=0.25 \mathrm{~cm})$.

$\bigcirc$ Single activation (row a, Table 2), $\square$ multiple activation (row b, Table 2), predicted by Eq. 3 (row g in Table 2).

coefficients and the experimental conditions for single (row a), multiple (row b), and no activation procedures (row c), respectively. The theoretical $I_{\mathrm{L}}$ (row g) from the Levich Eq. 3 using literature values for the diffusion coefficient and kinematic viscosity ${ }^{16}$ was calculated for reference.

The Levich plot with the single activation technique showed consistency with the theory up to $\omega^{0.5} \approx 20 \mathrm{rad}^{0.5}$ $\mathrm{s}^{-0.5}$. At higher $\omega$, the limiting current values decrease significantly leading to an apparent diffusion coefficient of 0.92 $\times 10^{-6} \mathrm{~cm}^{2} \mathrm{~s}^{-1}$. If the deviation of the experimental diffusion coefficient respect to the predicted value is defined as $\left(D_{\text {predicted }}-D_{\text {experimental }}\right) / D_{\text {predicted }}$, an error of $85 \%$ resulted for this procedure. The diffusion coefficient calculated from the multiple activation process was $6.05 \times 10^{-6} \mathrm{~cm}^{2} \mathrm{~s}^{-1}$, which represents an error of $3 \%$ from the predicted value.
Similarly, the diffusion coefficient obtained for an inactivated electrode (row c, Table 2, not show in Figure 2) shows a deviation of $36 \%$ from the predicted value. It is clear from these data that the multiple activation process correlates closely with the theoretical Levich equation. Whereas the theory states that the line should pass through the origin, the linear regression $\left(R^{2}=0.99\right)$ shows a small intercept 0.05 $\mathrm{mA} \mathrm{cm}{ }^{-2}$. This can be attributed to an additional background current, which is consistent with observations recorded in the absence of ferricyanide ion. The low values obtained for the diffusion coefficients from the procedures described earlier can be attributed to the build-up of oxides on the surface of the nickel electrode, according to the scheme ${ }^{30}$ :

$$
\mathrm{Ni} \stackrel{\text { aq. } \mathrm{KOH}}{\longrightarrow} \mathrm{Ni}(\mathrm{OH})_{2}-e^{-} \leftrightarrow \mathrm{NiO}(\mathrm{OH})+\mathrm{H}^{+}
$$

Over time, this reaction partially passivates the electrode, diminishing the surface area electrode, and hence reducing the limiting current. Therefore, it is crucial for the accurate measure of limiting current to "activate" the electrode to remove the surface oxide films before recording each linear sweep voltammogram.

\section{Activation in different electrolytes}

The importance of the activation step on the limiting currents values were measured at (i) inactivated nickel surface, (ii) nickel surface that had been activated in potassium hydroxide $\left(0.5 \mathrm{~mol} \mathrm{dm}^{-3}\right)$ with potassium ferricyanide been injected afterward, and (iii) nickel surface activated in an electrolyte in which measurements were taken, i.e., $\mathrm{NaOH}$ and $\mathrm{K}_{3} \mathrm{Fe}(\mathrm{CN})_{6}$. The Levich plots resulting from these experiments can be seen in Figure 3 together with the behavior predicted by the Levich equation. Both, the inactivated surface and the ferricyanide ion activated surface show significant departures from the predicted values. As pointed out earlier, the data obtained from the inactivated surface produced a diffusion coefficient of $4 \times 10^{-6} \mathrm{~cm}^{2} \mathrm{~s}^{-1}$, an error of $36 \%$ below the theoretical value (Table 2 , row c). The diffusion coefficient obtained from data using ferricyanide in $\mathrm{KOH}$-activated surface was $4.9 \times 10^{-6} \mathrm{~cm}^{2} \mathrm{~s}^{-1}$, which is still in error by $21 \%$ below (Table 2 , row d). The most likely reason for these low values is that the oxides have not been

Table 2. Tabulation of Diffusion Coefficients and Mass Transport Coefficients Calculated from Experimental Data Shown in Figures 2-4

\begin{tabular}{|c|c|c|c|c|c|c|c|c|}
\hline Series & $\begin{array}{l}\text { Electrode } \\
\text { Activation }\end{array}$ & $\begin{array}{l}\text { Electrolyte Used for } \\
\text { Activation }\end{array}$ & Substrate & $\begin{array}{c}\frac{d I_{\mathrm{L}}}{d \omega}\left(\mathrm{mA} \mathrm{cm}^{-2}\right. \\
\left.\operatorname{rad~s}^{-1}\right)\end{array}$ & $\begin{array}{c}D \\
\left(10^{-6} \mathrm{~cm}^{2} \mathrm{~s}^{-1}\right)\end{array}$ & $\begin{array}{l}\% \text { Error } \\
\text { in } D\end{array}$ & $\begin{array}{r}k_{\mathrm{m}}\left(R_{e}=3000\right) \\
\left(10^{-3} \mathrm{~cm} \mathrm{~s}^{-1}\right)\end{array}$ & $\begin{array}{l}\text { \% Error } \\
\text { in } k_{\mathrm{m}}\end{array}$ \\
\hline $\mathrm{a}$ & Single & $0.5 \mathrm{~mol} \mathrm{dm}-3 \mathrm{KOH}$ & Bulk nickel & 0.014 & 0.92 & 85 & 3.8 & 47 \\
\hline $\mathrm{b}$ & Multiple & $0.5 \mathrm{~mol} \mathrm{dm}^{-3} \mathrm{KOH}$ & Bulk nickel & 0.027 & 6.05 & 3 & 7.1 & 1 \\
\hline $\mathrm{c}$ & None & & Bulk nickel & 0.023 & 3.99 & 36 & 6.2 & 14 \\
\hline d & Multiple & $\begin{array}{l}0.5 \mathrm{~mol} \mathrm{dm}^{-3} \mathrm{KOH}+ \\
1 \times 10^{-3} \mathrm{~mol} \mathrm{dm}^{-3} \\
\mathrm{~K}_{3} \mathrm{Fe}(\mathrm{CN})_{6}\end{array}$ & Bulk nickel & 0.025 & 4.90 & 21 & 6.6 & 8 \\
\hline $\mathrm{e}$ & Multiple & $0.5 \mathrm{~mol} \mathrm{dm}^{-3} \mathrm{KOH}$ & $\begin{array}{l}\text { Electroplated } \\
\text { nickel }\end{array}$ & 0.025 & 4.93 & 20 & 6.6 & 7 \\
\hline f & Multiple & $0.5 \mathrm{~mol} \mathrm{dm}^{-3} \mathrm{KOH}$ & $\begin{array}{l}\text { Electroless } \\
\text { plated nickel }\end{array}$ & 0.014 & 0.92 & 85 & 3.8 & 47 \\
\hline g (theory) & - & - & - & 0.027 & 6.20 & 0.0 & 7.1 & $(0.0)$ \\
\hline
\end{tabular}

The percentage of error in $D$ is the amount that the diffusion coefficient values separate from the value calculated from the theory, Eq. 3 . Multiple activation consisted on activating the electrode surface prior to each linear sweep, while in the single activation the electrode was activated once, at the start, and then all experiments were performed on the same surface with no further activation. 


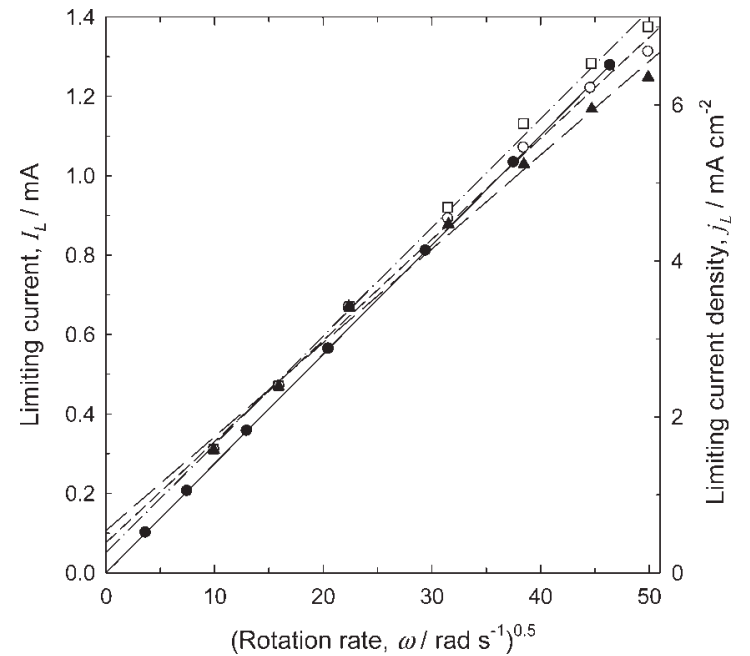

Figure 3. Levich plot of limiting current density $\left(i_{L}\right)$ vs. square root of rotation speed for the reduction of ferricyanide ions in $1 \times 10^{-3} \mathrm{~mol}$ $\mathrm{dm}^{-3} \mathrm{~K}_{3} \mathrm{Fe}(\mathrm{CN})_{6}+10 \times 10^{-3} \mathrm{~mol} \mathrm{dm}^{-3}$ $\mathrm{K}_{4} \mathrm{Fe}(\mathrm{CN})_{6}$ in $0.5 \mathrm{~mol} \mathrm{dm}^{-3} \mathrm{KOH}$ at an activated nickel $\operatorname{RDE}(r=0.25 \mathrm{~cm})$.

Comparison of activations performed in different electrolytes; $\boldsymbol{\Delta}$ inactivated (row c, Table 2), $\bigcirc 0.5 \mathrm{~mol} \mathrm{dm}^{-3}$ $\mathrm{KOH}+1 \times 10^{-3} \mathrm{~mol} \mathrm{dm}^{-3} \mathrm{~K}_{3} \mathrm{Fe}(\mathrm{CN})_{6}$ (row d, Table 2), $\square 0.5 \mathrm{~mol} \mathrm{dm}^{-3} \mathrm{KOH}$ (not shown in Table 2), and $\bullet$ predicted from Eq. 3.

fully removed by the polishing process and the surface area is smaller; there is also an increase in the $I R$ drop of the surface as a result. The activation process reduces some of the ferricyanide ion to ferrocyanide ion, hence diminishing the bulk concentration, but not significantly to cause large errors in the diffusion coefficient. The hydroxide-activated nickel electrode followed by the injection of ferricyanide ion gave a diffusion coefficient of $5.98 \times 10^{-6} \mathrm{~cm}^{2} \mathrm{~s}^{-1}$, a small error of $<4 \%$ (not shown in Table 2).

\section{Effect of the nature of the nickel electrode surface}

Many types of nickel surface are now available to the electrochemist, including electroplated and electroless nickel, both of which offer financial benefits over increasingly expensive bulk nickel. The reduction of ferricyanide ion was studied on these nickel surfaces: (a) bulk nickel, (b) electroplated nickel, and (c) electroless plated nickel. The data are illustrated as Levich plots in Figure 4, and the respective experimental conditions and diffusion coefficients values are presented in Table 2, rows b, e, and f. As can be seen from the Figure, the curve obtained on the bulk nickel surface closely adheres to the predicted Levich line, whilst the data on the electroplated nickel surface give rise to higher limiting currents. The diffusion coefficient calculated on electroplated nickel (row e) was $4.9 \times 10^{-6} \mathrm{~cm}^{2} \mathrm{~s}^{-1}$, nearly $20 \%$ lower than the predicted value. The higher currents can be attributed to the porous nature of the electroplated nickel (which causes an increase in the electroactive area), as reported by Notter and Gabe. ${ }^{27}$ The electroless-plated nickel (which is actually a $\mathrm{Ni}-\mathrm{P}$ alloy with a complex surface ${ }^{31}$ ] gives a diffusion coefficient of $0.92 \times 10^{-6} \mathrm{~cm}^{2} \mathrm{~s}^{-1}$, an error of more than $85 \%$ (row f, Table 2). It can be concluded from these results that plated nickel is an unsuitable material for limiting current measurements, and that only bulk nickel is suitable for such work under the present experimental conditions.

\section{Effect of polishing a nickel surface electrode}

Altering the surface area of the nickel RDE can have a dramatic effect upon the limiting current as calculated from the Levich Eq. 3. To quantify the importance of the surface finish of the nickel electrodes, four nickel RDEs were prepared by wet polishing followed by roughening with (a) 1200-grade silicon carbide paper, (b) 200-grade silicon carbide paper, (c) $5-\mu \mathrm{m}$ alumina, and (d) $0.1-\mu \mathrm{m}$ alumina. The effect on the reduction of $\mathrm{Fe}(\mathrm{CN})_{6}^{3-}$ at the nickel surface electrode rotating at $2000 \mathrm{rpm}$ can be seen in Figure 5. All the curves show long, well-defined plateaux and, if the actual surface area is taken into account, the calculated diffusion coefficients are within $5 \%$ of the predicted values. If, as more likely, diffusion coefficients were measured using the two-dimensional geometrical measurement of surface area, then the calculations would be as much as $90 \%$ inaccurate. It is essential to do both; polish the electrode well with finegrain alumina $(\leq 1.0 \mu \mathrm{m})$ and use the two-dimensional area value to calculate the diffusion coefficient, which would be the best method when the electrodes are easily accessible, i.e., flat surfaces. Alternatively, the calculation can be done more accurately if the value of the projected three-dimensional electroactive area is known. The latter is probably of more use in systems where the electrodes are less accessible (e.g. inside an enclosed, high-pressure system) or cannot be successfully polished (e.g. very thin electrodes). It is also

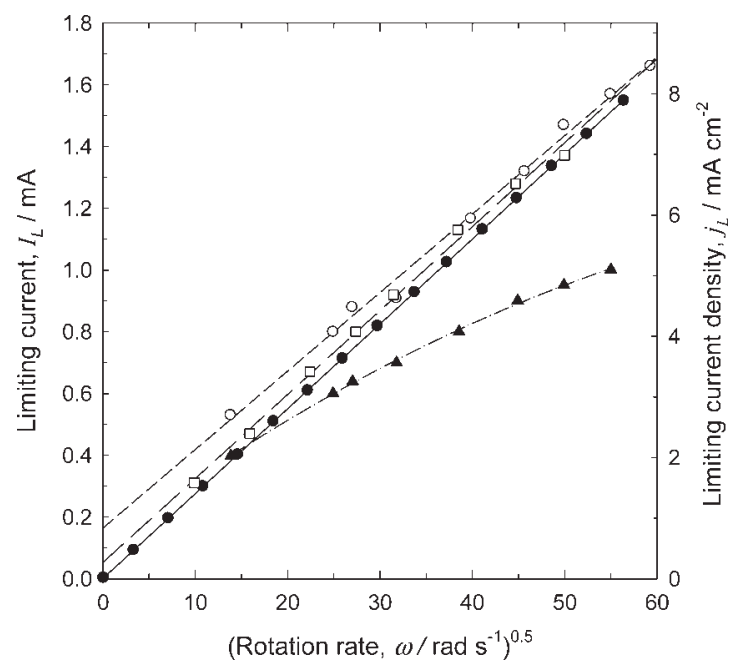

Figure 4. Levich plot of limiting current density $\left(j_{L}\right)$ vs. square root of rotation speed for the reduction of ferricyanide ions in $1 \times 10^{-3} \mathrm{~mol} \mathrm{dm}^{-3}$ $\mathrm{K}_{3} \mathrm{Fe}(\mathrm{CN})_{6}+10 \times 10^{-3} \mathrm{~mol} \mathrm{dm}^{-3} \mathrm{~K}_{4} \mathrm{Fe}(\mathrm{CN})_{6}$ in $0.5 \mathrm{~mol} \mathrm{dm}^{-3} \mathrm{KOH}$ at three activated nickel $\operatorname{RDE}(r=0.25 \mathrm{~cm})$.

Comparison of substrate; $\square$ bulk nickel (row b, Table 2), $\bigcirc$ electroplated nickel (row e, Table 2), $\mathbf{A}$ electroless plated nickel (row f, Table 2), and predicted from Eq. 3. 


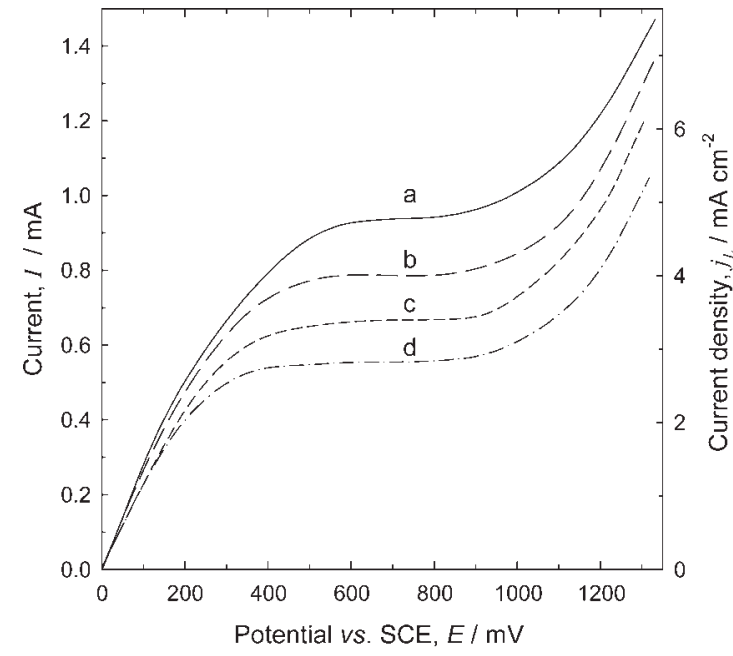

Figure 5. Linear sweep voltammograms of the reduction of ferricyanide ion in $1 \times 10^{-3} \mathrm{~mol} \mathrm{dm}^{-3}$ $\mathrm{K}_{3} \mathrm{Fe}(\mathrm{CN})_{6}+10 \times 10^{-3} \mathrm{~mol} \mathrm{dm}^{-3} \mathrm{~K}_{4} \mathrm{Fe}(\mathrm{CN})_{6}$ in $0.5 \mathrm{~mol} \mathrm{dm}^{-3} \mathrm{KOH}$ ) at a nickel RDE, $r=$ $0.25 \mathrm{~cm}$ rotating at $2000 \mathrm{rpm}$, following various polishing regimes.

(a) 1200-grade $\mathrm{SiC}$ paper, (b) 200-grade $\mathrm{SiC}$ paper, (c) 5- $\mu \mathrm{m}$ $\mathrm{Al}_{2} \mathrm{O}_{3}$, and (d) $0.1-\mu \mathrm{m} \mathrm{Al}_{2} \mathrm{O}_{3}$.

important to realize that the Levich treatment is restricted to laminar flow to a flat surface; the presence of surface roughness on a scale similar to that of the Nernst diffusion layer will complicate the hydrodynamics of the electrolyte.

\section{Effect of electroactive species decomposition}

The exposure of aqueous ferricyanide ion to direct sunlight is known to have a significant poisoning effect, ${ }^{3}$ according to the reaction:

$$
\mathrm{Fe}(\mathrm{CN})_{6}^{4-}+\mathrm{H}_{2} \mathrm{O} \stackrel{h v}{\longrightarrow} \mathrm{Fe}(\mathrm{CN})_{5} \cdot \mathrm{H}_{2} \mathrm{O}^{3-}+\mathrm{CN}^{-}
$$

This is followed by hydrolysis of free cyanide to generate hydroxyl ions:

$$
\mathrm{CN}^{-}+\mathrm{H}_{2} \mathrm{O} \rightarrow \mathrm{HCN}+\mathrm{OH}^{-}
$$

The cyanide ion can rapidly poison the nickel electrode, leading to a higher overpotential for $\mathrm{Fe}(\mathrm{CN})_{6}^{3-}$ reduction and degradation of the limiting current plateau. In order to qualitatively assess this effect, the change of potential with time of a nickel RDE was monitored in a series of solutions when a constant cathodic current density of $-0.8 \mathrm{~mA} \mathrm{~cm}{ }^{-2}$ was applied. The working electrode rotated at $1000 \mathrm{rpm}$ in a single compartment cell and the chronoamperometric studies were carried out in different solutions kept in (a) dark room, (b) brown glass, and (c) clear glass cell in sunlight. The initial overpotential was $-370 \mathrm{mV}$ vs. SCE in all cases. After $100 \mathrm{~h}$, no significant change in potential was seen in the cell kept in the darkness. The electrolyte in the brown cell glass showed no signs of red coloration, and the working electrode potential reached only $-480 \mathrm{mV}$ vs. SCE after $100 \mathrm{~h}$. The cell exposed to sunlight in a clear glass rapidly developed a deep red color, and the potential slowly becomes more negative reaching less than $-1000 \mathrm{mV}$ vs. SCE after $100 \mathrm{~h}$. At this point, the nickel surface had lost its activity toward the reduction of ferricyanide ion and hydrogen evolution was the only electrode reaction.

Figure 6 shows the concentration of ferricyanide ion in $\mathrm{KOH}$ electrolyte vs. time under the three conditions outlined earlier; the curves clearly show an exponential decay in concentration resulting in a reduction of up to $10 \%$, even when the solution is kept in the dark. This would imply that all measurements taken from a 2-day old ferricyanide solution could have an error up to $10 \%$, even if all other precautions are satisfied. These results show that provided that an electrolyte solution is made up freshly for each experiment, there is however, practically no problem in using a covered cell under ambient conditions.

\section{Effect of background electrolyte}

Taama et al. ${ }^{26}$ attributed the low values of limiting current obtained over a period of time during the reduction of ferricyanide ion in $\mathrm{KOH}$ electrolyte to a yellowish film formed on the surface of a stainless steel electrode because of the high $\mathrm{pH}$ of this solution. They showed that, for a well-polished nickel, platinum, and stainless steel electrode surfaces, there is little difference in the initial value of limiting currents measured in potassium hydroxide or potassium carbonate electrolytes. However, after 100-min immersion in $\mathrm{KOH}$ electrolyte, the limiting current of ferricyanide reduction on nickel and stainless steel electrodes dropped by $25 \%$ and $30 \%$, respectively, while the limiting current on the platinum electrode remained unchanged. Since $\mathrm{KOH}$ is a common electrolyte used to evaluate limiting current and there is no noticeable degradation in the current potential shape, there is no visual alert that the results are not reliable. When $\mathrm{K}_{2} \mathrm{CO}_{3}$ was used as a background electrolyte, the limiting current values decreased only $3 \%$ on a stainless steel electrode,

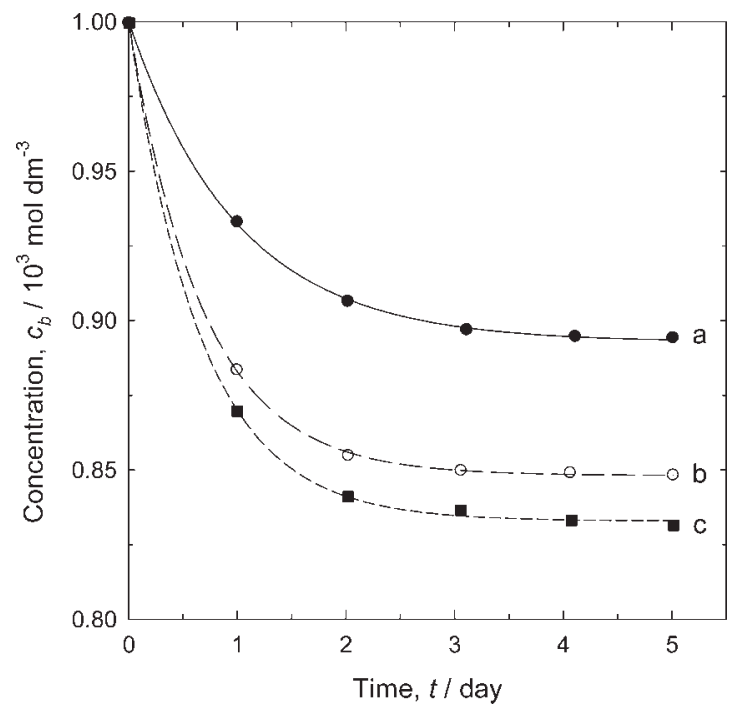

Figure 6. Concentration of ferricyanide ion vs. time.

The initial concentration of ferricyanide was $1 \times 10^{-3} \mathrm{~mol}$ $\mathrm{dm}^{-3}$ as $\mathrm{K}_{3} \mathrm{Fe}(\mathrm{CN})_{6}$, and the solutions were stored in (a) a darkened room, (b) brown glass bottles, and (c) clear glass bottles in sunlight. 


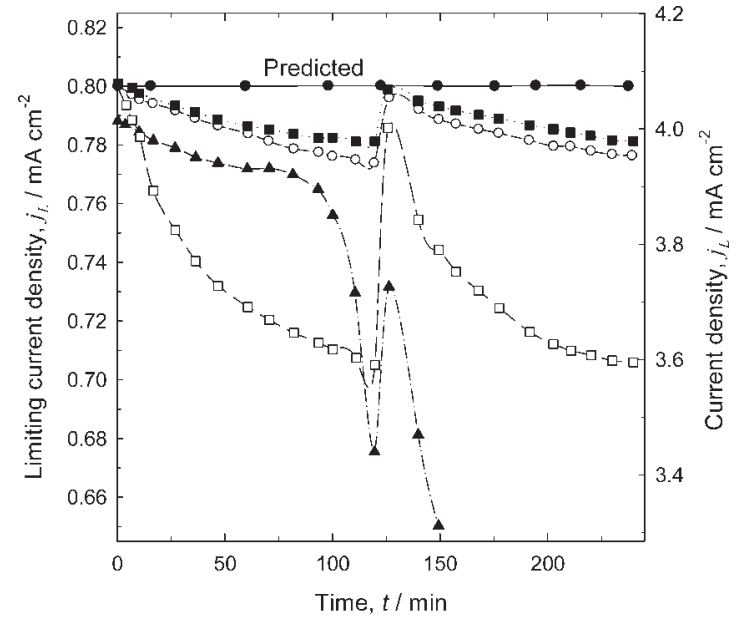

Figure 7. The relationship between limiting current density and time for ferricyanide ion reduction in $1 \times 10^{-3} \mathrm{~mol} \mathrm{dm}^{-3} \mathrm{~K}_{3} \mathrm{Fe}(\mathrm{CN})_{6}$ at a nickel RDE rotating at $3000 \mathrm{rpm}, r=0.25$ $\mathrm{cm}$ ), in different supporting electrolytes at $0.5 \mathrm{~mol} \mathrm{dm}^{-3}$ concentration.

$\square \mathrm{KOH}, \bigcirc \mathrm{K}_{2} \mathrm{CO}_{3}, \boldsymbol{\square} \mathrm{KNO}_{3}, \boldsymbol{\Delta} \mathrm{K}_{2} \mathrm{SO}_{4}, \bullet$ predicted by
Eq. 3 .

whereas no change was observed on nickel and platinum electrodes over a period exceeding $120 \mathrm{~min}$. This was attributed to the low $\mathrm{pH}$ that inhibited the creation of the yellowish film formed in more alkaline solutions.

In this work, the experiments reported by Taama et al. ${ }^{26}$ were repeated adding two extra electrolytes: potassium nitrate and potassium sulphate. The former has been used as a background electrolyte for $\mathrm{Fe}(\mathrm{CN})_{6}^{3-}$ reduction, ${ }^{3}$ whereas there is no record of sulphate being used.

The importance of choosing a suitable background electrolyte is shown in Figure 7. $\mathrm{K}_{2} \mathrm{SO}_{4}, \mathrm{~K}_{2} \mathrm{CO}_{3}, \mathrm{KNO}_{3}$, and $\mathrm{KOH}$ solutions, each at $0.5 \mathrm{~mol} \mathrm{dm}{ }^{-3}$, were used with a constant $1 \times 10^{-3} \mathrm{~mol} \mathrm{dm}^{-3}$ concentration of $\mathrm{Fe}(\mathrm{CN})_{6}^{3-}$. The limiting current for $\mathrm{Fe}(\mathrm{CN})_{6}^{3-}$ reduction was measured at a nickel $\mathrm{RDE}$, using a rotation speed of $3000 \mathrm{rpm}$ and a constant potential of $-600 \mathrm{mV}$ vs. SCE (corresponding to a point near the centre of the limiting current plateau). The current was measured at $\sim 10$-min intervals over a period of 250 min. To investigate whether the changes on the limiting current were due to a film formation, the electrodes were polished after the first $2 \mathrm{~h}$ and returned to the same solution. For comparison purposes, a time-independent limiting current of $0.8 \mathrm{~mA} \mathrm{~cm}^{-2}$ is shown as the value predicted by the Levich Eq. 3 in Figure 7. The current values were corrected for the different viscosities by normalizing to the $\mathrm{KOH}$ viscosity in order to allow direct comparison. The experimental limiting current value obtained in $\mathrm{KOH}$ solution dropped from 0.80 to $0.71 \mathrm{~mA} \mathrm{~cm}^{-2}$ in the first $2 \mathrm{~h}$, a decrease of $\sim 11 \%$. In the second 2 -h period after cleaning the electrode, the limiting current value approached the theoretical value but dropped over time in a similar fashion as in the first 2-h period. The limiting current values obtained in $\mathrm{K}_{2} \mathrm{CO}_{3}$, dropped from 0.80 to $0.77 \mathrm{~mA} \mathrm{~cm}^{-2}$, a drop of only $3 \%$ in comparison with the theoretical value and similar to the result obtained by Taama et al. ${ }^{26}$ In the next $2 \mathrm{~h}$, a similar behavior was observed; return to the theoretical value and 3\% drop with time. In the case of the $\mathrm{KNO}_{3}$ electrolyte solution, the limiting current dropped from 0.8 to $0.78 \mathrm{~mA} \mathrm{~cm}^{-2}$, a drop of only $2.5 \%$ with similar behavior during the second 2-h period. The value obtained in $\mathrm{K}_{2} \mathrm{SO}_{4}$ electrolyte solution, however, started at slightly lower value and dropped $17 \%$ from 0.78 to $0.65 \mathrm{~mA} \mathrm{~cm}{ }^{-2}$; after cleaning, the electrode showed signs of recovery but quickly dropped again and after $150 \mathrm{~min}$ had fallen nearly $80 \%$ to a current value below $0.1 \mathrm{~mA} \mathrm{~cm}{ }^{-2}$. Current potential curves recorded during these experiments showed that the degradation in the current applies to the limiting current plateau and that neither the overall shape of the curves are greatly affected, nor are the hydrogen evolution potentials.

\section{Conclusions}

This study shows the importance of the experimental procedures for the measurement of limiting currents using the reduction of $\mathrm{Fe}(\mathrm{CN})_{6}^{3-}$ at nickel electrodes. Table 2 shows the effect of experimental conditions on two common uses for limiting current values, namely the treatment of diffusion coefficients and mass transport coefficients. A comparison was made between these results and those obtained from the literature. ${ }^{21}$ Mass transport coefficients have been calculated for a Reynolds number of 3000 , corresponding to an RDE of $0.5 \mathrm{~cm}$ radius rotating at $1500 \mathrm{rpm}$, and errors can be seen to range from $<1 \%$ in the best case to almost $50 \%$ in the worst case.

The most suitable procedure for the determination of convective-diffusion controlled limiting currents involves the following procedures:

(1) The reduction of ferricyanide ion at a nickel electrode and $\mathrm{KOH}$ as a supporting electrolyte is a common system for mass transport measurements. Incorrect preparation and procedures can lead to inaccurate values.

(2) Where possible, the electrode should be carefully polished before each experiment, e.g., using fine-grade alumina (typically $0.1 \mu \mathrm{m}$ ). Failing this, the electroactive surface should be accurately measured.

(3) The electrode should be activated before each linear sweep experiment, by allowing hydrogen to evolve at the working electrode. A suitable procedure would be to activate for $10 \mathrm{~min}$ at a current density of $10 \mathrm{~mA} \mathrm{~cm}{ }^{-2}$.

(4) This activation of electrode surfaces is best performed in the background electrolyte alone (containing no ferricyanide ion) activating in the electrolysis solution and then taking a sample in order to calculate the resultant concentration of ferricyanide ion, one can obtain acceptable results in some cases.

(5) Electrolytes should be freshly prepared before each experiment and studies should, where possible, be performed in the absence of direct sunlight.

\section{Notation}

\footnotetext{
$A=$ area of rotating disc electrode $\left(\mathrm{cm}^{2}\right)$

$c_{\mathrm{b}}=$ bulk concentration of ferricyanide ion in the electrolyte $\left(\mathrm{mol} \mathrm{cm}{ }^{-3}\right)$

$D=$ diffusion coefficient of ferricyanide ion $\left(\mathrm{cm}^{2} \mathrm{~s}^{-1}\right)$

$F=$ Faraday constant, 96,485 $\left(\mathrm{C} \mathrm{mol}^{-1}\right)$

$I_{\mathrm{L}}=$ limiting current (for the convective-diffusion controlled reduction of ferricyanide ion) (A)
} 


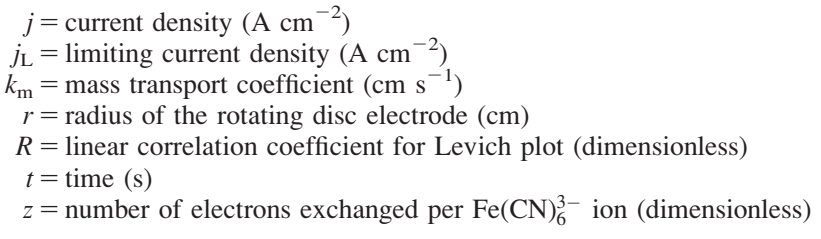

\section{Greek letters}

$\eta=$ overpotential $(\mathrm{V})$

$v=$ kinematic viscosity of electrolyte $\left(\mathrm{cm}^{2} \mathrm{~s}^{-1}\right)$

$\omega=$ angular velocity of $\operatorname{RDE}\left(\operatorname{rad~s}^{-1}\right)$

\section{Acknowledgments}

The authors gratefully acknowledge stimulating discussions with Prof. G. H. Kelsall and EPSRC sponsorship to Dr. D. A. Szánto.

\section{Literature Cited}

1. Walsh FC. A First Course in Electrochemical Engineering, 1st ed. Romsey, U.K.: The Electrochemical Consultancy, 1993.

2. Pletcher D, Walsh FC. Industrial Electrochemistry, 2nd ed. London: Chapman and Hall, 1991.

3. Selman JR, Tobias CW. Mass-transfer measurements by the limitingcurrent technique. Adv Chem Eng. 1978;10:211-318.

4. Ponce-de-León C, Field RW. On the determination of limiting current density from uncertain data. J Appl Electrochem. 2000;30:10871090.

5. Burns JR, Jachuck RJJ. Determination of liquid-solid mass transfer coefficients for a spinning disc reactor using a limiting current technique. Int J Heat Mass Transfer. 2005;48:2540-2547.

6. Ponce-de-León C, Low CTJ, Kear G, Walsh FC. Strategies for the determination of the convective-diffusion limiting current from steady state linear sweep voltammetry. J Appl Electrochem. 2007; 37:1261-1270.

7. Pletcher D. A First Course in Electrode Processes, 1st ed. Romsey, U.K.: The Electrochemical Consultancy, 1993.

8. Wragg AA. Applications of the limiting diffusion current technique in chemical engineering. Chem Engr (London). 1977;316:39-44, 49.

9. Scannell RA, Walsh FC. Comparative mass transfer and electrode area in electrochemical reactors. Inst Chem Engr Symp Ser. 1989; 112:59-71.

10. Taama WM, Plimley RE, Scott K. Mass transfer rates in a DEM electrochemical cell. Electrochim Acta. 1996;41:543-548.

11. Griffiths M, Ponce-de-León C, Walsh FC. Mass transport in the rectangular channel of a filter-press electrolyser (the FM01-LC reactor). AIChE J. 2005;51:682-687.

12. Berger FP, Ziai A. Optimisation of experimental conditions for electrochemical mass transfer measurements. Chem Eng Res Des. 1983; 61:377-382.
13. Alkire R. Transport processes in electrochemical systems. Chem Eng Commun. 1985;38:401-413.

14. Eisenberg M, Tobias CW, Wilke CR. Ionic mass transfer and concentration polarization at rotating electrodes. I Electrochem Soc. 1954;101:306-319.

15. Brown CJ, Pletcher D, Walsh FC, Hammond JK, Robinson D. Local mass transport effects in the FM01 laboratory electrolyser. $J$ Appl Electrochem. 1992;22:613-619.

16. Brown CJ, Pletcher D, Walsh FC, Hammond JK, Robinson D. Studies of space-averaged mass transport in the FM01-LC laboratory electrolyzer. J Appl Electrochem. 1993;23:38-43.

17. Brown CJ, Pletcher D, Walsh FC, Hammond JK, Robinson D. Studies of three-dimensional electrodes in the FMO1-LC laboratory electrolyser. J Appl Electrochem. 1994;24:95-106.

18. Marracino JM, Coueret F, Langlois S. First investigation of flowthrough porous electrodes made of metallic felts or foams. Electrochim. Acta. 1987;9:1303-1309.

19. Montillet A, Comiti J, Legrand J. Application of metallic foams in electrochemical reactors of the filter-press type. II. Mass transfer performance. J Appl Electrochem. 1994;24:384-389.

20. Quickenden TI, Xu Q. Toward a reliable value for the diffusion coefficient of cupric ion in aqueous solution. J Electrochem Soc. 1996; 143:1248-1253.

21. Newman J. Schmidt number correction for the rotating disk. J Phys Chem. 1966;70:1327-1328.

22. Barcia OE, Lamego LSR, Mattos OR, Tribollet B. The modulated flow at a rotating hemispherical electrode. J Electrochem Soc. 2001;148:C1-C9.

23. Sedahmed GH, Al-Abd MZ, El-Taweel YA, Darwish MA. Liquidsolid mass transfer behaviour of rotating screen discs. Chem Eng J. 2000;76:247-252.

24. Djati A, Brahimi M, Legrand J, Saidani B. Entrance effect on mass transfer in a parallel plate electrochemical reactor. J Appl Electrochem. 2001;31:833-837.

25. Rizk TY, Thompson GW, Dawson JL. Mass transfer enhancement associated with sudden flow expansion. Corros Sci. 1996;38:1801-1814.

26. Taama WM, Plimley RE, Scott K. Influence of supporting electrolyte on ferricyanide reduction at a rotating disc electrode. Electrochim Acta. 1996;41:549-551.

27. Notter IM, Gabe DR. Porosity of electrodeposited coatings: its cause, nature, effect and management. Corros Rev. 1992;10:217-280.

28. Canning W. The Canning Handbook: Surface Finishing Technology, 23rd ed. Birmingham: Canning and Company, 1982.

29. Szanto DA. Characterisation of Electrochemical Filter-Press Reactors. Ph.D. Thesis, University of Portsmouth, U.K., 1999.

30. Amjad M, Pletcher D, Smith C. Oxidation of alcohols at a nickel anode in alkaline $t$-butanol/water mixtures. J Electrochem Soc. 1977; 2:203-206.

31. Reidel W. Electroless Nickel Plating. New Jersey: ASM International, 1995.

Manuscript received Jun. 15, 2007, revision received Sept. 24, 2007, and final revision received Dec. 4, 2007. 